\author{
I.N. Zakharova ${ }^{1}$, A.N. Goryainova ${ }^{1}$, N.V. Koroid ${ }^{2}$, L.B. Torshkhoeva ${ }^{1}$, I.B. Lagadze $^{1}$ \\ 1 Russian Medical Academy of Postgraduate Education of the RF MH (Ministry of Health), \\ Moscow \\ 2 Tushino Children's Municipal Hospital of Moscow, Russian Federation
}

\title{
Therapy of acute respiratory infections in children: novelties
}

\section{Author affiliation:}

Zakharova Irina Nikolaevna, $\mathrm{PhD}$, Professor, head of the department of pediatrics of the Russian Medical Academy of Postgraduate Education (State Budgetary Educational Institution) of the RF MH (Ministry of Health), Honored Doctor of the Russian Federation

Address: 2/1 Barrikadnaya Str., Moscow, 123995, tel.: +7 (495) 496-52-38, e-mail: kafedra25@yandex.ru

\section{Article received: 21.10.2013. Accepted for publication: 14.01.2014.}

Acute respiratory infections (ARIs) are the most widespread pathology in children not only in Russia, but also in other developed countries. According to R. Garibaldi [1] and Fendrick et al. [2], 75-100 mn medical appointments on account of ARIs take place in the USA annually, whereas expenses on over-the-counter and prescription drugs reach 2.9 \$bn and 400 \$mn per year. The number of schooldays skipped due to ARIs vary from 22 to $189 \mathrm{mn}$; the total economic loss exceeds 20 \$bn.

The most ARI-susceptible group is children of 1-5 years of age due not only to immune system formation and functioning peculiarities (the development completes by 7-10 years of age), but also to age-related anatomical and physiological peculiarities of upper and lower airways: abundance of blood and lymph vessels, mucosal tenderness, relative narrowness of nasal chambers and bronchial tree, poor development of paranasal sinuses and high mucosal viscosity. According to the trials performed at the $3^{\text {rd }}$ contagious isolation ward of the Tushino municipal children's hospital (TMCH) of Moscow, immune system of small children with ARIs is characterized by low amount of T lymphocytes (CD3+) in every second child. More than $70 \%$ of children with these infections have low CD4 and CD8 subpopulations of T lymphocytes, more than 30\% - of B lymphocytes [3-5]. Blood serum immunoglobulin (Ig) A, M, G content analysis indicates that ca. $50 \%$ of the children have low level of serum $\operatorname{IgG}$, considerably fewer - of IgM and $\operatorname{IgA}(11.3 \pm 4.0$ and $6.5 \pm 3.1 \%$, respectively). However, analysis of nasal washing secretory IgA content demonstrated that nasal washing $\operatorname{SIgA}$ level was lower than normal $(\mathrm{p}<0.001)$ in most patients $(75.8 \pm 5.4 \%$ ). Levels of serum interferons (IFN) $\alpha$ and $\gamma$ were below the sensitivity threshold of test systems $(<2 \mathrm{pg} / \mathrm{ml})$ in more than $60 \%$ of the patients $(\mathrm{tb} .1)$. Induced IFN $\alpha$ production below $300 \mathrm{pg} / \mathrm{ml}$ was revealed in $22.6 \%$ of the patients; induced IFN $\gamma$ production below $200 \mathrm{pg} / \mathrm{ml}$ was revealed in $40.4 \%$ of small children [6, 7]. Average levels of nasal washing IFN $\alpha$ were below the sensitivity threshold of test systems $(<2 \mathrm{pg} / \mathrm{ml})$ in every third child, of nasal washing IFN $\gamma-$ in every second.

The latest issue of the Nelson Essentials of Pediatrics [8] emphasizes that acute respiratory tract infections in children have certain peculiarities:

- take place every (!) year;

- the morbidity peak takes place in the cold months of the year;

- preschool-aged children develop ARIs more often (6-7 per year on the average);

- $\quad 10-15 \%$ of children may develop ARIs up to 12 times per year;

- the older the child, the lower the ARI rate (down to 2-3 times per year in adolescence);

- the children attending organized bodies develop ARIs much more often (more than 50\% more often). 
ARIs in children do not usually take a severe course, which is why parents or relative do not always seek medical advice. That is why there are no exact statistical data on the number of ill children. In most cases, ARI clinical pattern is predominated by symptoms of rhinorrhea and nasal congestion (nasal obstruction); it may feature fever; there is no systemic disease manifestation, which is why it is possible to monitor patients on the outpatient basis. However, in several cases children (especially small children) have to be hospitalized due to the risk of complications development or the existing complications.

The trials performed at the contagious isolation ward for small children at the TMCH demonstrated that $82.4 \%$ of children ( 1 month -3 years of age) are admitted to the hospital in moderate condition. However, only $22 \%$ out of the 91 examined children featured non-complicated ARI form. $40.7 \%$ of the patients were hospitalized with diagnosis "Acute bronchitis"; obstructive syndrome develops concurrently with acute bronchitis in $73 \%$ of the patients (tb. 2).

Despite non-severe course of most ARIs, it ought to be remembered that acute respiratory tract infections have socioeconomic consequences and are characterized by certain material expenses (which may be considerable for household budgets). Socioeconomic consequences of ARIs are as follows: child's social deadaptation, potential risk of pedagogical problems, family psychological climate alteration (strained relations between parents, lack of attention to all the other family members), family life quality decline. ARIs cause unwarranted material expenses suffered by the family due to waste of the parents' working hours and therapy expenses. Moreover, frequent ARIs negatively affect children's health and stimulate formation of chronic diseases of upper and lower respiratory tracts and cause exacerbation of the existing chronic diseases.

Several terms are used in the process of diagnosing children with symptoms of acute infectious respiratory diseases.

1. ARIs - general name of a range of clinically similar acute infectious respiratory diseases, which may be caused by bacteria, viruses, mycoplasmas and chlamydiae.

2. ARVIs are a group of clinically and morphologically similar acute infectious respiratory diseases, which may be caused by viruses only.

3. Common colds - the term used in the Nelson Essentials of Pediatrics [8] to refer to ARI seasonal rate.

The modern classification of diseases (ICD-10) employs headings J00-J06 for acute upper respiratory infections:

J00 Acute nasopharyngitis;

J01 Acute sinusitis;

J02 Acute pharyngitis;

J02.0 Streptococcal pharyngitis;

J02.8 Acute pharyngitis due to other specified organisms;

J02.9 Acute pharyngitis, unspecified;

J03 Acute tonsillitis;

J03.0 Streptococcal tonsillitis;

J03.8 Acute tonsillitis due to other specified organisms;

J08.9 Acute tonsillitis, unspecified;

J04 Acute laryngitis and tracheitis;

J05 Acute obstructive laryngitis [croup] and epiglottitis;

J06 Acute upper respiratory infections of multiple and unspecified sites;

J06.9 Acute upper respiratory infection, unspecified.

Up to $97 \%$ of acute respiratory infections in children are due to viruses, especially rhinoviruses and coronaviruses. ARIs are less often caused by respiratory-syncytial viruses, influenza, parainfluenza and adenoviruses. Regardless of the causative agent, ARIs take the classical acute inflammatory response course: infiltration or the upper respiratory tract's mucosa by inflammatory cells and cytokine release. Unlike the patients who did not need inpatient 
treatment, the hospitalized children were mostly affected by influenza virus [9]; adenovirus or respiratory-syncytial viral infections are detected far less often (6.1 and 10.2\%, respectively; tb. 3).

It has been determined that more than $50 \%$ of the hospitalized $0-3$-year-old children were diagnosed with monoviral infections; both viral (13.2\%) and viral-bacterial (27.5\%) associations may be found in the other patients. Bacteriological test of pharyngeal swabs revealed opportunistic and pathogenic microflora in $38 \%$ of the patients; two or more causative agents (dominated by streptococci) were identified in $52 \%$ of cases.

Analysis of virus identification rate throughout the epidemic season revealed wide fluctuations in the registration of various types of viruses (pic. 1). Thus, e.g., March was dominated by influenza A viruses (H1N1), May-June - by influenza B viruses [9].

Despite the fact that almost all viruses provoke similar symptoms (fever, intoxication accompanied by weakness, malaise, anorexia, nausea and emesis, symptoms of inflammation of oro- and nasopharyngeal, upper and lower respiratory tract mucosae) [10], many viruses cause distinctive syndromes, which help to predict the possible etiology of the infectious disease on the basis of the clinical data.

Influenza is diagnosed on the basis of sudden body temperature rise to fever (sometimes up to $40{ }^{\circ} \mathrm{C}$ and higher), marked intoxication, chill, adynamia, myalgiae and headaches, dry cough characterized by transsternal pain and posterior pharyngeal wall hyperemia. Fever usually persists for 3 days. Severe cases may be characterized by central nervous system dysfunctions and hemorrhagic rashes. The distinctive feature of influenza virus is the ability to cause pandemics.

Parainfluenza is manifested with fever, catarrhal phenomena, pharyngotonsillitis and pseudocroup syndrome, development of bronchitis and bronchiolitis. The most susceptible group to parainfluenza is 2-3-year-old children.

Respiratory-syncytial (RS) viral infection is characterized by clinical pattern of bronchitis and bronchiolitis with marked bronchoobstructive syndrome and respiratory failure. Toxicosis symptoms are moderate. The common feature of parainfluenza and RS-infection is the lack of durable immunity, which is why these virus are of high danger, especially for children with immunodeficiency symptoms; the outbursts may take form of hospital-acquired infections.

Adenovirus infection does not have a strict seasonal character; it is registered throughout the year in the form of sporadic cases and, sometimes, outbursts; takes a far milder course than influenza. Adenovirus infection is characterized by gradual descending affection of respiratory tracts, oropharyngeal lymphoid tissue hyperplasia and expansion of cervical lymph nodes (virus reproduction takes place not only in epithelium, but also in lymphoid tissue). Adenovirus infection is distinguished by involvement of anatomically different systems in the pathological process: mucosae of respiratory tract, eyes, intestines and liver (up to hepatitis). The disease's clinical pattern usually develops from weakness, malaise, body temperature rise to low-grade fever to the body temperature of $38{ }^{\circ} \mathrm{C}$ and higher. Nasal congestion may be moderate; examination of children reveals hyperemia and edematous tonsils, palatal arches and posterior pharyngeal wall. Rhinitis may be accompanied by conjunctivitis (which is usually catarrhal, although severe forms - follicular, membranous or hemorrhagic conjunctivitis - may take place).

Rhinovirus infection is distinguished by lack or insignificant intensity of general symptoms [8] and predominant affection of nasal and nasopharyngeal mucosae. The clinical pattern is predominated by symptoms of rhinosinusitis. Rhinovirus infection is spread all over the world, though it is more often registered in countries with frigid and temperate climate. The highest morbidity rate is observed in the children attending organized bodies. Abundant rhinorrhea and need in using handkerchiefs results in hyperemia and maceration of nasal vestibular skin in children.

Recently, infectologists have been giving much consideration to coronavirus infection; marked rhinitis persisting for 7 days without body temperature rise most often develops secondary to this disease. Pain in swallowing, sneezing, headache and cough may take place. Body temperature is 
usually normal or slightly high. General intoxication symptoms are usually mild; however, in rare cases the disease may take a severe course in children (up to bronchitis, pneumonia, cervical lymphadenopathy).

Bocavirus infection (human bocavirus was first described in 2005) causes upper and lower respiratory diseases. The primary clinical forms of bocavirus infection are rhinitis, acute catarrhal otitis media, tonsillitis, pharyngitis, laryngotracheites, pneumonia, bronchitis and bronchiolitis [11]. Bronchoobstructive syndrome may also develop rather often. The most frequent symptoms of bocavirus infection in children are cough (which if often paroxysmal, similar to pertussis), rhinorrhea, fever and respiratory problem. The most susceptible age group is 1-3-year-old children; the bocavirus infection morbidity peak is registered in OctoberNovember.

Metapneumovirus infection (human metapneumovirus was discovered in 2001) is most often diagnosed in 1-7-year-old children and usually takes its course as rhinopharyngitis. Bronchitis may develop. Cough, rhinorrhea and nasal congestion may simultaneously occur in the first days of the disease. Up to $90 \%$ of children with metapneumovirus infection have fever, which may persist for 5-7 days. Intestinal symptoms (emesis, diarrhea) are diagnosed in 19\% of children. Complications of the disease are as follows: acute otites media, pulmonary atelectases and pericardites [12].

Children with acute respiratory viral infections (ARVI) and influenza are in most cases treated outpatiently by means of regimen measures, adequate water supply, sparing diet, etiotropic and palliative therapy (pic. 2). It ought to be mentioned that intensity of both general (flaccidity, malaise, headache, fatigue, fever etc.) and local (mucosal hyperemia of palatal tonsils and pharynx, cough, sneezing, rhinitis, nasal congestion, sore throat etc.) clinical symptoms may vary greatly. It depends on a large number of factors, the primary among which are disease etiology and individual and age-related peculiarities of a child's body. It ought to be noted that several respiratory viruses have affinity to certain areas of respiratory tract's epithelium and development of more pronounced inflammatory alterations in typical sites (nasal-pharyngeal or epiglottic/laryngeal, palatal tonsillar or bronchial-bronchiolar etc. mucosae).

It ought to be noted that etiotropic drugs reach maximal efficacy against ARVIs only if prescribed in and from the first hours of the disease. Apart from etiotropic drugs, complex treatment of children with ARVI and influenza includes palliative therapy. Palliative therapy at ARVI is aimed at reducing intensity of the clinical manifestations of the disease disturbing the child's general state. It usually involves antipyretics, decongestants and cough medicines. Pediatricians have a wide choice of antitussive drugs in order to terminate cough. They are discriminated on the basis of mechanism of action into cough suppressants, mucolytics and expectorants. Local decongestants are prescribed to terminate nasal obstruction - one of the most frequent symptoms of ARVI - in children.

Practical experience does not support the assumption that all viral infections activate bacterial flora (on the basis of, e.g., leukocytosis): ARVIs are tolerated well by most patients without intake of antibiotics. Antibacterial drugs may be indicated at ARVI and influenza for children with chronic pulmonary pathology and immunodeficiencies - patients with high risk of bacterial process exacerbation.

Modern approaches to the treatment of respiratory infections, palliative and etiotropic therapy provide for the use immunomodulators, including bacterial lysates, e.g., Broncho-Vaxom (OM Pharma, Switzerland), which includes lysates of the 8 bacteria inducing respiratory tract infections more often than any other bacteria (Klebsiella pneumonia and ozoenae, Haemophilus influenzae, Diplococcus pneumoniae, Staphylococcus aureus, Streptococcus pyogenes and viridans, Neisseria catarrhalis). Mechanism of action and dosage regimen allow using this drug both for treatment and preventive purposes in children over 6 months of age.

ARI prevention in children consists of several key aspects, which, on the one hand, are not excessively expensive, on the other, may not be performed easily due to objective reasons:

- $\quad$ prevention or maximal restriction of the child's contact with the infection source; 
- $\quad$ vaccination;

- cold treatment;

- $\quad$ rational age-adequate nutrition;

- $\quad$ formation of psychological comfort in the child's family and social circle;

- $\quad$ timely vitamin therapy (spring and autumn).

The existing need in developing new methods of ARI prevention is due to the following factors:

- $\quad$ ARI in children may be accompanied by respiratory tract obstruction; this requires hospitalization and emergency care rendering to children at specialized wards;

- $\quad$ The number of children with bronchial asthma has been increasing for 30 years;

- $\quad$ ARI as the cause of bronchial obstruction was confirmed in $80-85 \%$ of children with bronchial asthma.

In Western Europe, drugs based on bacterial lysates have been being used for ARI prevention since 1996. The first randomized placebo-controlled trials of bacterial lysates in children date back to 1986 [13], when J. Sramek et al. [14] did not obtain significant differences for intranasal use of IRS 19 as a prophylactic drug for acute infectious respiratory tract diseases in children (tb. 4).

In 1985 P. Binder et al. [15] proved immunostimulating effect of Broncho-Vaxom in young mice by means of an experiment with reference to the data obtained by J. Clot and M. Amdary published in journal "Medicine and Hygiene" (Geneva) in 1980.

C.H. Razi et al. [16] studied preventive prescription of the drug's formulation for children: a randomized double blind placebo-controlled trial in parallel groups demonstrated that obstructive syndrome rate in children with ARI had reduced by $37.9 \%$ since the beginning of using this drug for prevention in comparison with the control group (tb. 5).

The drug is used as an immunomodulators; its prescription to children is reasonable for the following reasons:

- It is a prophylactic drug for respiratory tract infections [17-24];

- It alleviates the course of chronic obstructive pulmonary diseases [16-18, 25], although the decrease in the rate of disease relapses in not always proven [26];

- It decreases rate and duration of obstructive syndromes [27, 28];

- Prescription of this drug for recurrent acute respiratory infections in children is economically sound [29].

F. Braido et al (2007) conducted a meta-analysis [13], on the basis whereof it became possible to formulate several propositions regarding mechanism of action of the tested drug:

1. Constituent bacterial structures interact with Toll-like receptors (which play the key role in innate immunity) located on the surface of macrophages of monocytes.

2. Interaction of Toll-like receptors and the drug's bacterial structures activates (stimulates) monocytes and macrophages and helps their differentiation into mature dendritic cells (antigenpresenting macrophages)

3. Antigen-presenting cells stimulate functioning of T-lymphocytes (especially of T-helpers) and B-lymphocytes and activate antibody synthesis.

The drug indirectly stimulates systemic and local immune response, immunoglobulin synthesis and cell-mediated immunity. According to the trials by B. Emmerich et al. (1990) [22], this drug positively affects the balance of T-helpers and T-suppressors of pulmonary tissue, improves generation of $\gamma$-interferon, stimulates activity of alveolar macrophages and normalizes synthesis of secretory IgA (whereas IgE synthesis drops).

Bacterial immunomodulators are prescribed to:

- $\quad$ Frequently ill children;

- Children with obstructive respiratory diseases;

- Children undergoing immunosuppressive therapy for prevention of acute respiratory infections; 
- Children attending organized bodies in periods of large-scale ARI and influenza morbidity.

Use of bacterial lysates, particularly, of Broncho-Vaxom, for prevention of acute infectious respiratory disease in children results not only in the drop of ARI rate, but also in a milder course of chronic obstructive pulmonary diseases and reduction in treatment expenses.

\section{REFERENCES}

1. Garibaldi R. A. Epidemiology of community-acquired respiratory tract infections in adults. Incidence, etiology, and impact. Am J Med. 1985 Jun 28;78 (6B): 32-7.

2. Fendrick A. M., Monto A. S., Nightengale B., Sarnes M. The economic burden of non-influenzarelated viral respiratory tract infection in the United States. Arch Intern Med. 2003 Feb 24; 163 (4): $487-$ 94.

3. Zakharova I.N., Cheburkin A.V., Malinovskaya V.V. et al. Importance of interferon system for immune response formation in children with acute respiratory viral infections. Voprosy prakticheskoi pediatrii - Problems of practical pediatrics. 2009; 4 (5): 38-45.

4. Zakharova I. N., Malinovskaya V. V., Torshkhoeva L. B. Clinical-immunological efficacy of using a drug based on recombinant IFN-A2 Viferon (suppositories and ointment) for treating acute respiratory infections in small children. Pediatriya-Pediatrics. 2011; 4: 28.

5. Zakharova I.N., Malinovskaya V.V., Korovina N.A. et al. Clinical-immunological substantiation of local interferon therapy for respiratory viral infections in children. Voprosy prakticheskoi pediatrii - Problems of practical pediatrics.2011; 6 (5): 21-26.

6. Zakharova I.N., Torshkhoeva L.B., Zaplatnikov A.L. et al. Interferon system peculiarities at acute respiratory infections and clinical-immunological efficacy of modified interferon therapy in small children. Efficient pharmacotherapy. Pediatriya - Pediatrics. 2011; 1: 70.

7. Zakharova I.N., Torshkhoeva L.B., Zaplatnikov A.L. et al. Modified interferon therapy for acute respiratory infections in small children: pathogenetic substantiation and efficacy. Rossiiskii vestnik perinatologii i pediatrii - Russian bulletin of perinatology and pediatrics. 2011; 56 (3): 49-54.

8. Nelson Essentials of Pediatrics (6th ed.). 2011. 831 p.

9. Malinovskaya V.V., Zakharova I.N., Isaeva E.I. et al. Etiological structure of acute respiratory infections in small children. Voprosy prakticheskoi pediatrii - Problems of practical pediatrics. 2010; 5 (5): 99-104.

10. Botvin'eva V.V., Aref'eva N.A., Aznabaeva L.F., Ivanova R.A., Romantsov M.G. Respiratornye zabolevaniya: etiopatogenez, klinika, lechenie, profilaktika. Rukovodstvo dlya vrachei [Respiratory Diseases: Etiopathogenesis, Clinical Pattern, Treatment, Prevention. Guidelines]. St. Petersburg, 2002. 48 p.

11. Shvets E.Yu. Kliniko-epidemiologicheskie osobennosti i diagnostika bokavirusnoi infektsii u detei. Avtoref. dis. ... kand. med. nauk [Clinical and Epidemiological Peculiarities and Bocavirus Infection Diagnostics in Children. Author's abstract]. Moscow, 2009. 24 p.

12. Kozulina I.S., Samsygina G.A., Isaeva E.I., Legkova T.P., Shevchenko I.M., Donin I.M., Pavlov S.A. Metapneumovirus infection in children. Pediatriya - Pediatrics. 2009; 88 (5): 58-62.

13. Braido F., Tarantini F., Ghiglione V., Melioli G., Canonica G.W. Bacterial lysate in the prevention of acute exacerbation of COPD and in respiratory recurrent infections. International Journal of COPD. 2007; 2 (3): 335-345.

14. Sramek J., Josifko M., Helcl J., Holoubkova E., Janout V., Kozesnik B., Macatova I. Bacterial lysate (I.R.S. 19) applied intranasally in the prevention of acute respiratory diseases in children: a randomized double-blind study. J Hyg Epidemiol Microbiol Immunol. 1986; 30 (4): 377-85.

15. Binder P., Gendre F., Huart B., Paucod J.C., Deschaux P., Fontan ges R. Immunomodulation in offspring mice after neonatal immunostimulation of mothers or newborn mice. Tohoku J Exp Med. 1985 Aug; 146 (4): 379-83.

16. Razi C., Harmanci K., Abaci A., Ozdemir O., Hizli S., Renda R., Keskin F. The immunostimulant OM-85 BV prevents wheezing attacks in preschool children. J Allergy Clin Immunol. 2010; 126: 763-9. 17. Schaad U., Mutterlein R., Goffin H. BV-child study group. Immunostimulation with OM-85 in children with acute recurrent infections of the upper respiratory tract. Chest. 2002; 122: 2042-9. 
18. Gutierrez-Tarango M., Berber A. Safety and efficacy of two courses of OM- 85 BV in the prevention of respiratory tract infections in children during 12 months. Chest. 2001; 119: 1742-8.

19. Schaad U. Prevention of paediatric respiratory tract infections: emphasis on the role of OM-85. Eur Respir Rev. 2005; 14: 74-7.

20. Maestroni G., Losa G. Clinical and immunobiological effects of an orally administered bacterial extract. Int J Immunopharmacol. 1984; 6: 111-7.

21. Berber A., Del-Rio-Navarro B. Use of Broncho-Vaxom in private practice: phase IV trial in 587 children. Clin Ther. 1996 Nov-Dec; 18 (6): 1068-79.

22. Emmerich B., Emslander H., Milatovic D., Hallek M., Pachmann K. Effects of a bacterial extract on local immunity of the lung in patients with chronic bronchitis. Respiration. 1990; 57 (2): 90-9.

23. Soler M., Mutterlein R., Cozma G. Double-Blind Study of OM-85 in Patients with Chronic Bronchitis or Mild Chronic Obstructive Pulmonary Disease. Respiration. 2007; 74: 26-32.

24. Carmona-Ramirez M., Alvarez-Gomez V., Berber A. Use of OM-85 BV for the Prevention of Acute Respiratory Tract Infections in Occupational Medicine. The Journal of International Medical Research. 2002; 30: 325-329.

25. Navarro S., Cossalter G., Chiavaroli C., Kanda A., Fleury S., Lazzari A., Cazareth J., Sparwasser T., Dombrowicz D., Glaichenhaus N., Julia V. The oral administration of bacterial extracts prevents asthma via the recruitment of regulatory T cells to the airways. Mucosal Immunology. 2011; 4 (1): 53-65.

26. Steurer-Stey C., Bachmann L., Steurer J., Tramer M. R. Oral purified bacterial extracts in chronic bronchitis and COPD: systematic review. Chest. 2004 Nov; 126 (5): 1645-55.

27. Jonston S., Pattermore P., Sanderson G., Smith S., Lampe F., Josephs S. et al. Role of virus infections in exacerbations in children with recurrent wheeze or cough. Thorax. 1993; 48: 1055.

28. Jonston S., Pattermore P., Sanderson G., Smith S, Lampe F., Josephs L., Symington P., O'Toole S., Myint S.H., Tyrrell D.A. et al. Community study of role of viral infections in exacerbations of asthma in 9-11 year old children. BMJ. 1995; 310: 1225-9.

29. Pessey J. J., Megas F., Arnould B., Baron-Papillon F. Prevention of recurrent rhinopharyngitis in atrisk children in France: a costeffectiveness model for a nonspecific immunostimulating bacterial extract (OM-85 BV). Pharmacoeconomics. 2003; 21 (14): 1053-68.

Table 1. Initial values of interferon (IFN) system parameters at acute respiratory viral infection in small children

\begin{tabular}{|c|c|c|c|}
\hline \multirow{2}{*}{ Parameter } & \multicolumn{2}{c|}{ IFN value, pg/ml (n = 62) } \\
\cline { 2 - 4 } & $\mathrm{M} \pm \mathrm{m}$ & $\mathrm{Me}[\mathrm{Q} 1 ; \mathrm{Q}]$ \\
\hline \multicolumn{3}{|c|}{ Interferon status } \\
\hline Serum IFN $\alpha$ & $4.3 \pm 1.2$ & $0[0 ; 3.0]$ \\
\hline \multirow{2}{*}{ IFN $\alpha$ generation } & Spontaneous & $<2.0$ & $<2.0$ \\
\cline { 2 - 4 } & Induced & $1,054.2 \pm 132.4$ & $619.8[327.0 ; 1,572.1]$ \\
\hline \multicolumn{2}{|c|}{ Serum IFN $\gamma$} & $4.9 \pm 1.8$ & $0[0 ; 5.4]$ \\
\hline IFN $\gamma$ generation & Spontaneous & $4.1 \pm 0.9$ & $1.2[0 ; 4.3]$ \\
\cline { 2 - 4 } & Induced & $668.5 \pm 120.0$ & $276.9[103.0 ; 781.0]$ \\
\hline \multicolumn{3}{|c|}{ Nasopharyngeal wash interferons } \\
\hline IFN $\alpha$ & $6.6 \pm 1.2$ & $3.7[1.0 ; 7.8]$ \\
\hline \multicolumn{2}{|c|}{ IFN $\gamma$} & $11.8 \pm 1.9$ & $5.3[0 ; 21.5]$ \\
\hline
\end{tabular}

Table 2. Clinical forms of acute respiratory infection (ARI) in hospitalized patients

\begin{tabular}{|l|c|}
\hline \multicolumn{1}{|c|}{ Clinical ARI forms } & Rate, \% \\
\hline Non-complicated form & 22 \\
\hline Acute bronchitis & 40.7 \\
\hline Obstructive syndrome in children with acute bronchitis & 73 \\
\hline Acute otitis & 26.4 \\
\hline Acute tonsillitis & 8.8 \\
\hline Pneumonia & 6.6 \\
\hline Two disease forms & 12.1 \\
\hline
\end{tabular}


Table 3. Structure of monoviral infections in hospitalized patients

\begin{tabular}{|l|c|}
\hline \multicolumn{1}{|c|}{ Viral infection variant } & Rate, $\%$ \\
\hline Influenza & 61.2 \\
\hline Adenoviruses & 6.1 \\
\hline RS-viruses & 10.2 \\
\hline Parainfluenza & 4.4 \\
\hline Rhinoviruses & 2 \\
\hline Metapneumoviruses & 8.2 \\
\hline Bocaviruses & 8.2 \\
\hline
\end{tabular}

Table 4. Randomized controlled trials in children receiving bacterial lysates [13]

\begin{tabular}{|l|c|c|}
\hline \multicolumn{1}{|c|}{ Author } & Year & $\begin{array}{c}\text { Number of } \\
\text { patients }\end{array}$ \\
\hline J.P. Collet et al. & 1993 & 423 \\
\hline D. Gomez Barreto et al. & 1998 & 56 \\
\hline Gutierrez-Tarango, A. Berber & 2001 & 54 \\
\hline B.E. Del Rio Navarro et al. & 2003 & 40 \\
\hline F. Rosaschino, L. Cattaneo & 2004 & 89 \\
\hline S.B. Ruah et al. & 2001 & 188 \\
\hline U.B. Schaad, R. Mutterlein, H. Goffin & 2002 & 232 \\
\hline $\begin{array}{l}\text { J. Sramek et al. (intranasal IRS 19 without significant differences } \\
\text { from a placebo) }\end{array}$ & 1986 & 1,252 \\
\hline S. Zagar, D. Lofler-Badzek & 1998 & 51 \\
\hline
\end{tabular}

Table 5. Effect of bacterial lysates on the course of acute respiratory infections (ARI) in children within an observation year [16]

\begin{tabular}{|l|c|}
\hline \multicolumn{1}{|c|}{ Symptom } & Symptom rate decline, \% \\
\hline Obstructive syndrome & 37.9 \\
\hline ARI rate & 31.4 \\
\hline Nasopharyngitis & 37.5 \\
\hline
\end{tabular}


Pic. 1. Etiological structure of acute respiratory viral infections in children by months Note. ${ }^{*}-\mathrm{p}<0.05 ; * *-\mathrm{p}<0.01 ; * * *-\mathrm{p}<0.001$.

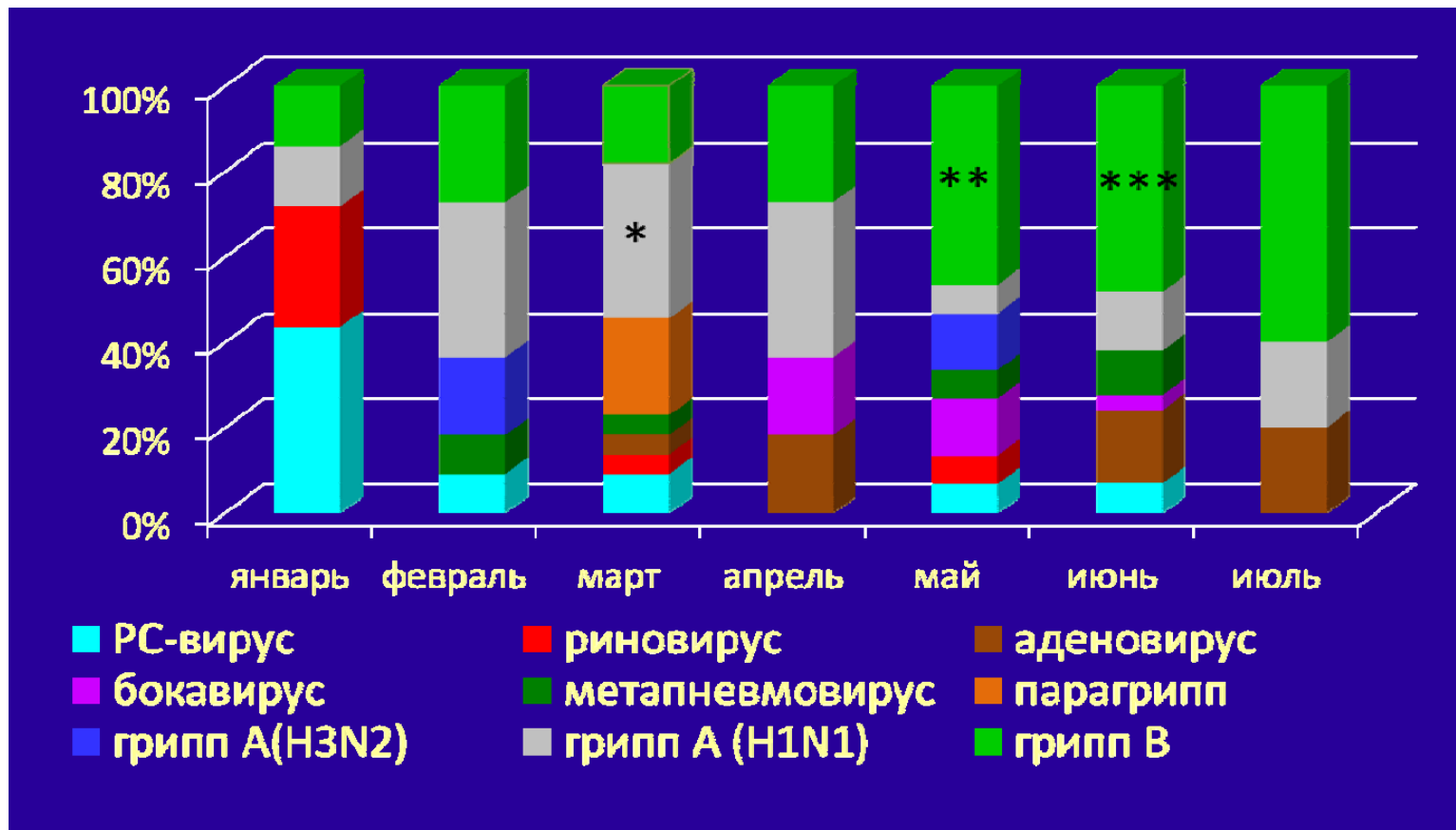

\begin{tabular}{|l|l|}
\hline январь & January \\
\hline февраль & February \\
\hline март & March \\
\hline апрель & April \\
\hline май & May \\
\hline июнь & June \\
\hline июль & July \\
\hline РС-вирус & RS-virus \\
\hline бокавирус & Bocavirus \\
\hline грипп A (H3N2) & Influenza A (H3N2) \\
\hline риновирус & Rhinovirus \\
\hline метапневмовирус & Metapneumovirus \\
\hline грипп A (H1N1) & Influenza A (H1N1) \\
\hline аденовирус & Adenovirus \\
\hline парагрипп & Parainfluenza \\
\hline грипп В & Influenza B \\
\hline
\end{tabular}


Pic. 2. Main principles of treating respiratory infections

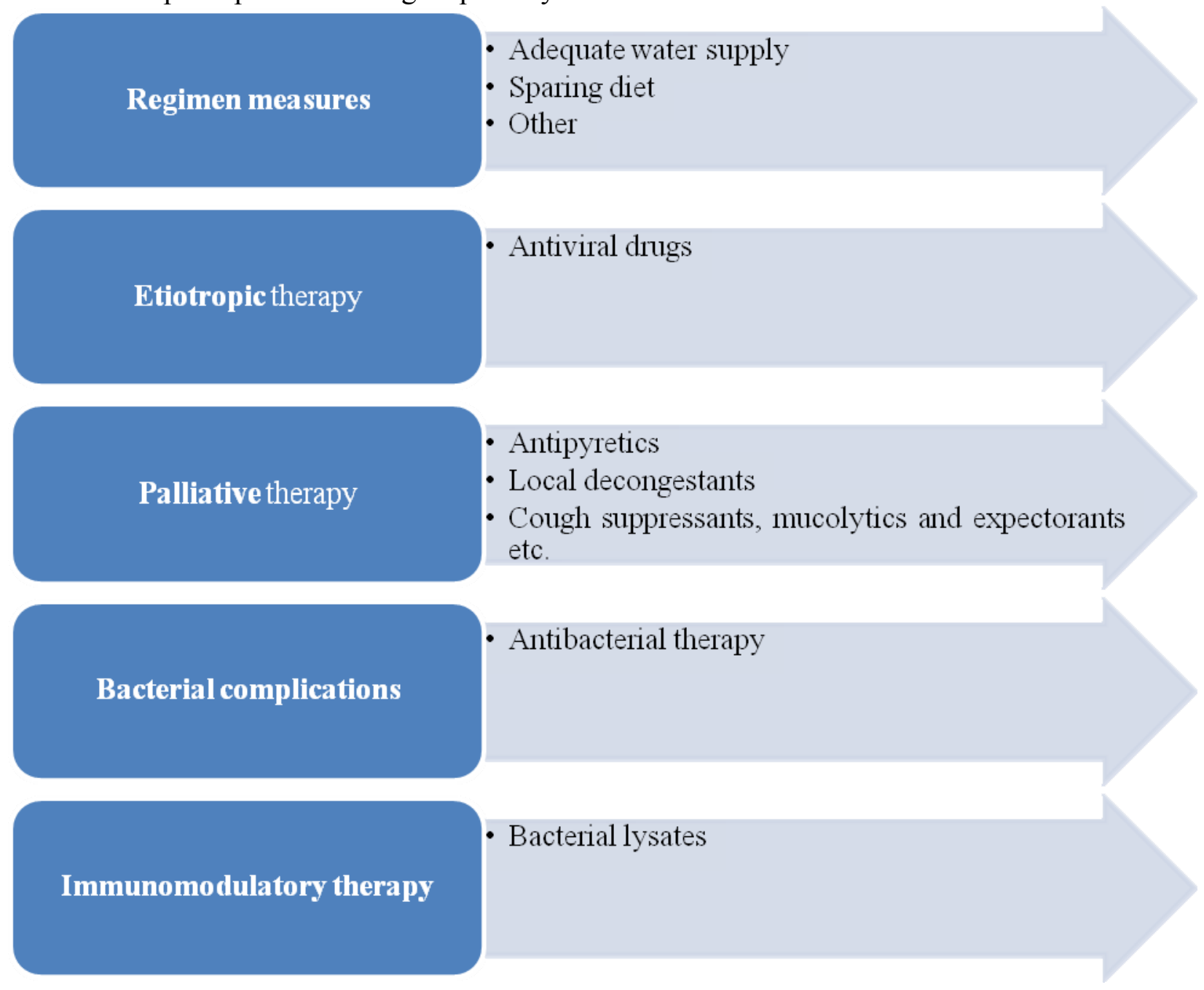

